\title{
Significant factors affecting the selection of rational options for power supply in an off-grid zone
}

Irina Ivanova*, Melentiev Energy Systems Institute of Siberian Branch of the Russian Academy of Sciences, Irkutsk, Russia

\begin{abstract}
The paper presents a short characteristic of an off-grid zone in the eastern regions of the Russian Federation. The main problems of power supply to consumers in this zone are described, and possible options for solving them are provided. A methodological approach and model tools to estimate the efficiency of alternative options of power supply to off-grid consumers are described. The factors affecting the selection of a rational option of power supply in the off-grid zone are classified. We show the interconnection between the main significant factors (availability of grid infrastructure, local fuel resources, complexity of fuel delivery logistics, characteristics of accessible power-generating equipment, and environmental constraints) and their impact on economic indicators of alternative options. Based on the systematized results of long-term studies, we present a scheme designed to select a rational option of power supply to a particular off-grid consumer according to characteristics of the described factors. Keywords: Off-grid consumers, alternative options, impact of factors, economic indicators, methodological approach, simulation models, economic efficiency.
\end{abstract}

\section{Introduction}

Most of the off-grid hard-to-reach and remote regions in Russia are provided with power from power plants with a unit capacity below $25 \mathrm{MW}$. More than $30 \%$ of capacity of small power plants functions in the eastern territories. The total installed capacity of the power plants in East Siberia is estimated to be $750 \mathrm{MW}$, and in the Far East - $1450 \mathrm{MW}$ [1]. Power output from the small power plants in East Siberia is about $1.1 \mathrm{bn} \mathrm{kWh}$, and power generated in the Far East amounts to $1.8 \mathrm{bn} \mathrm{kWh}$. Many small power plants are used as backup plants at the ends of extended radial transmission lines, and at social facilities (boiler plants, hospitals, etc.). However, the bulk of the small power plants are autonomous power sources in small settlements dispersed in a vast territory.

More than $60 \%$ of the installed capacity of small power plants in East Siberia are in operation in the northern regions of Krasnoyarsk Territory and Irkutsk Region; and in

\footnotetext{
* Corresponding author: nord@isem.irk.ru
} 
Sakha (Yakutia) Republic, Amur Region, and Khabarovsk Territory - in the Far East (Fig. $1)$.

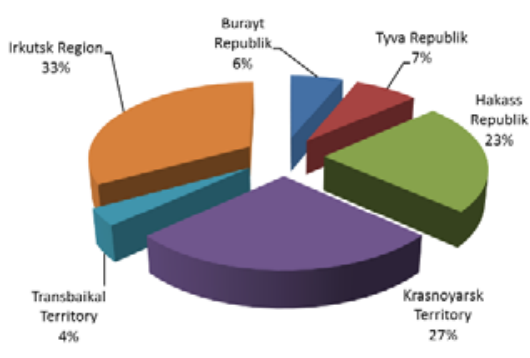

East Siberia

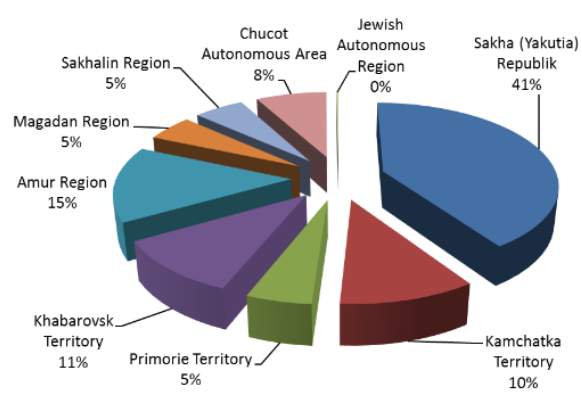

Far East

Note: compiled based on the 2016 ROSSTAT forms

Fig. 1. Distribution of small power plant capacity by eastern entity of the RF

Over the last years, there has been a trend towards a considerable growth in the capacity of such power plants in Krasnoyarsk Territory, Irkutsk Region, and Sakha (Yakutia) Republic. This fact is explained by the more intensive development of hydrocarbon deposits located in the off-grid zone in the northern areas of these Entities of the Russian Federation. Apart from new industrial consumers, there are many settlements that receive electricity from small municipal power plants (most often diesel ones) with a capacity from tens of kilowatts to tens of megawatts.

Power supply to the off-grid consumers is characterized by high costs, which is caused by low concentration of loads, and poorly developed transport and energy infrastructures. Seasonally limited delivery periods and the need to create large fuel supplies lead to high quantitative and qualitative losses. This problem is especially acute when coal is transported at long distances $[1,2]$. The transportation component of the fuel cost for the most remote and hard-to-reach consumers reaches $70-80 \%$. Consequently, the diesel fuel price increases to 50-65 thousand Rub/ton, and the cost price of electricity generation reaches $30-50 \mathrm{Rub} / \mathrm{kWh}$. To keep the rates for the population at an admissible level, the federal and the local budgets (or through cross subsidization) appropriate considerable subsidies to equalize the rates and maintain power sources.

The main solution to the accumulated problems of power supply in the off-grid zone is to diversify the electricity production. The options to be viewed as an alternative to the traditional power supply from diesel power plants (DPP) should include:

- connection to the grid (where possible);

- adoption of cogeneration plants using local fuels: coal and natural gas from smallscale deposits;

- use of renewable energy sources (RES);

- construction of low-capacity nuclear power plants.

An important factor is to organize the production of oil products and liquefied natural gas at low-tonnage plants in the territories of hydrocarbon extraction, and a subsequent change in the fuel delivery logistics.

\section{A methodological approach and model tools to assess the efficiency of the off-grid power supply options}


Over the years, we have been studying the rational options of power- and fuel supply to off-grid consumers in the eastern regions of the RF [3-6]. We have developed some information -computer systems that include the analytical block that contains various information, a two-level methodological block, and a block of model tools to comprehensively analyze the efficiency of different power supply options (Fig. 2).

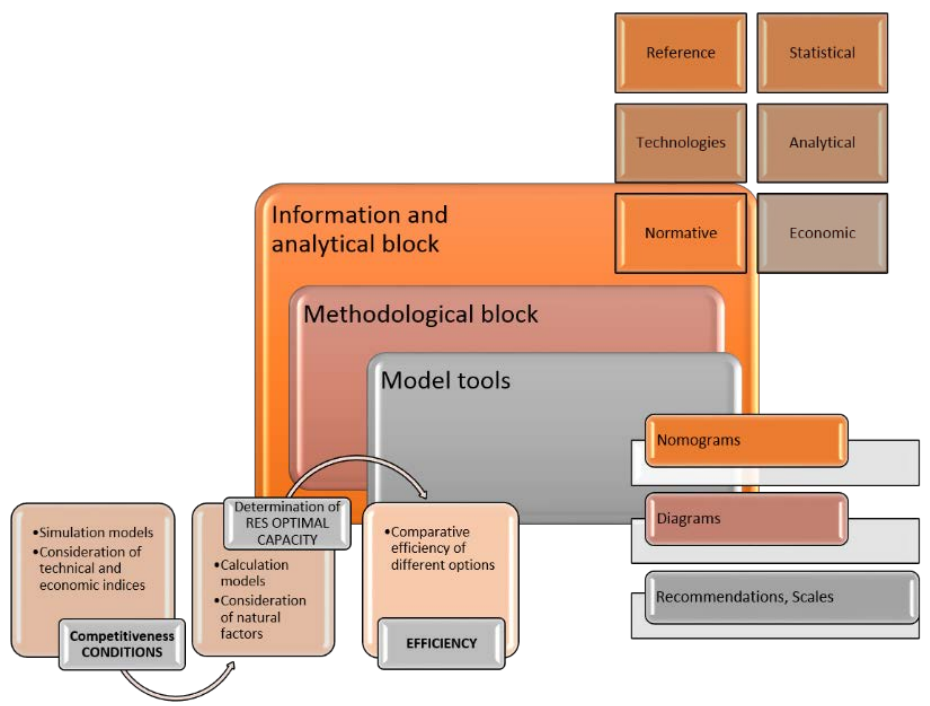

Fig. 2. Information resources to estimate the efficiency of the off-grid power supply options

The two levels considered in the methodological approach make it possible, based on the results of the studies for the regional level, to reduce the amount of preparatory and analyzed information for the local level by cutting down the number of technologically and economically feasible options.

At the regional level, based on the aggregate calculations depending on the main cost indices, we determine the conditions for economic competitiveness of all the technologically possible power supply options in the given territory. To conduct the studies at this level, we have developed a system of simulation models, which is based on the standard method of technical and economic comparison of alternative power supply options by the total discounted costs for their implementation provided there is an equal energy effect.

As a result of the studies at this level, we obtain nomograms that determine if it is appropriate to consider in detail a power supply option for each off-grid consumer in the region. Selection of the most rational option is based on the assessment of financial and economic effectiveness of each of the chosen options.

All the addressed prospective power supply options make it possible to reduce the fuel delivery compared to the traditional scheme, and, thus, lower the annual budget subsidies for the maintenance of the power sources. Therefore, most often, we assess project's budget efficiency whose main indicator is the cumulative subsidies from the budget over the service life of the facility. A more in-depth description of the methodological approach and the main principles of the model tools are presented in [7]. 


\section{Factors affecting the selection of a rational power supply option}

The long-term research revealed the significant factors that influence the selection of a rational option of power supply to off-grid consumers. These factors may be divided into several groups: geographical, technological, infrastructural, and environmental (Fig. 3).

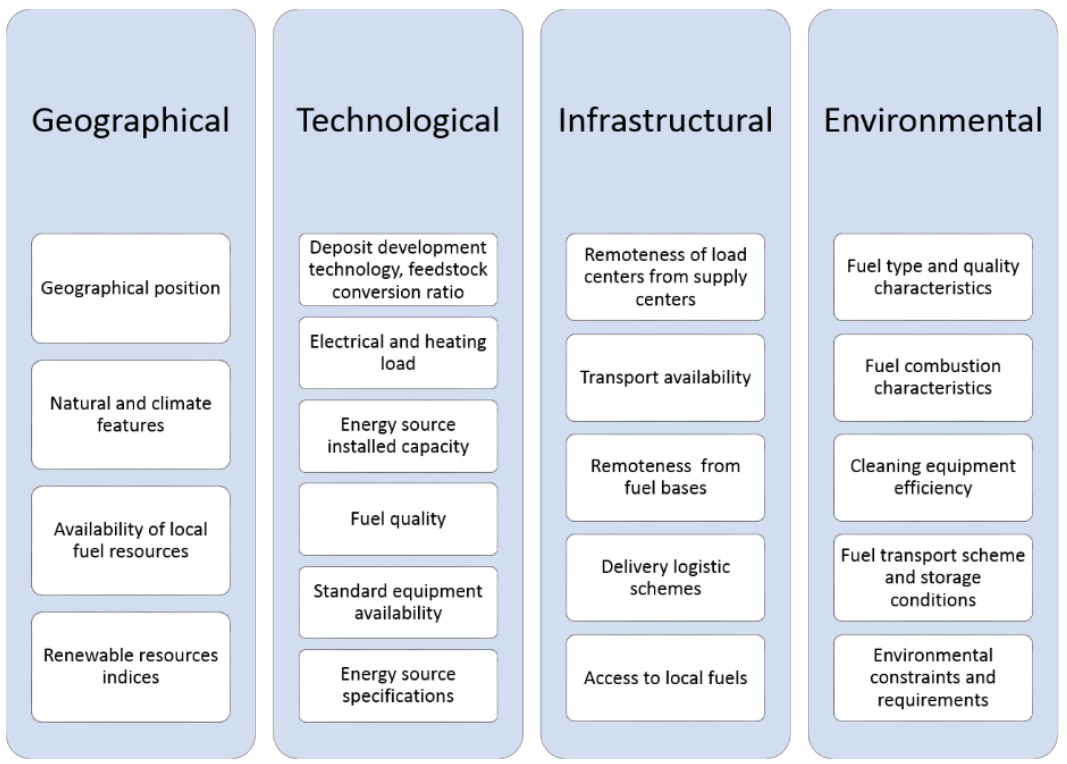

Fig. 3. Factors affecting the efficiency of alternative power supply options

Geographical factors are basic (exogenous), and affect, directly and indirectly, technological and infrastructural factors.

Geographic position of an enterprise developing a deposit affects the selection of logistics schemes for delivery of equipment, fuel, materials, etc. This factor is the main, when determining the status of a settlement (a rotation camp, a permanent residence, a possibility to involve the staff from nearest settlements), which, in turn, affects the power loads and, as a consequence, the type of power source to be chosen.

Natural and climate features of the territory characterize the environmental conditions under which the anthropogenic load may form, as well as the ability of the environment to self-restore without subsequent changes in the initial state. This factor is the most important for Arctic territories, where self-regulation processes are weakened, biological diversity is unique, and the climatic conditions are severe.

The availability of local fuel resources is a determining factor when making a decision on possible consideration of an option of fuel supply to a power facility on the basis of these resources. The efficiency of a certain small deposit development and qualitative characteristics of the fuel to be obtained play an important role in this case.

The indices of renewable energy resources affect whether or not the renewable energy source is included in a set of alternative power supply options. For wind farms, the initial indices include the magnitude, variability and stability of the wind speed during the year; for photovoltaic plants, these are the intensity and annual distribution of solar radiation indices; for mini hydro power plants, the initial indices are represented by the riverbed 
slope, current speed, annual runoff variation, possibility of small watercourse frost penetration.

Technological factors affect the selection of types and characteristics of generating equipment. The technology of deposit development (for mining enterprises), feedstock conversion ratio and processing technology (for processing enterprises) determine the character (profile) and level of power loads. According to power load, the consumers are subdivided into household and industrial including mining and processing plants. The character and the level of loads, as well as the fuel quality at the consumption site, influence the value of the energy source installed capacity, whereas the availability of standard equipment intended for the Arctic environment determines the mix of the power source equipment.

Infrastructural factors characterize the transport and energy accessibilities for the consumer. Remoteness of load centers and energy systems from supply centers is one of the key parameters in addition to the power load, when considering the possibility of centralized power supply to the consumer. An important factor, in this case, is the load of the existing transformer substation and a transmission line of the power supply center, as well as the presence and the load of potential consumers along the assumed transmission line route.

The transport accessibility of the consumer affects directly the fuel pricing for the consumer, and, thus the efficiency of the power supply scheme itself. Due to remoteness from fuel bases, for the majority of consumers in the northern territories of the eastern regions, fuel, as well as all the other cargos, are delivered by a complex transport scheme with two-three transshipments. The delivery for the most hard-to-reach consumers last two years, and requires special storage conditions at the sites of inter-navigation deposition.

The accessibility to local coal- and gas-fields affects whether or not this fuel supply option will be included in a set of alternative ones. The logistics of the fuel delivery to a consumption site influences the cost and the quality of both local fuel and fuel delivered from other regions.

Environmental factors are some kind of limitations when selecting an option of power supply. They include the volumes of emissions/discharges and amount of production and consumption waste. The environmental factors are largely interconnected with one another: the type of a power source to be selected determines the equipment configuration, fuel combustion process, volume and composition of pollutant emissions, whereas the fuel selection, in turn, affects the type of the power source, etc. The transportation scheme and the fuel storage conditions affect, basically, the quality of coal, because its characteristics considerably deteriorate, when the transportation has many stages, lasts long and involves intermediate storage.

All the enumerated factors are interconnected with one another and affect directly the formation of economic indices of the power supply options: the price of the delivered fuel, the cost of local fuel resources, the equipment cost, the electricity rates at the load center, investment. The economic indices, in turn, determine the total costs of the entire operation cycle of an energy facility. These costs are used as the main criterion when substantiating a rational power supply option. Fig. 4 shows schematically the interconnections between the main significant factors and their impact on the economic indices of alternative power supply options.

\section{Research results}

The revealed significant factors that affect the composition and parameters of power supply options can be assessed using quantitative or qualitative characteristics. These characteristics of the factors can serve as criteria for the classification of consumers in order 
to make unified guidelines for selecting alternative options of power supply to the off-grid zone in the region at issue.

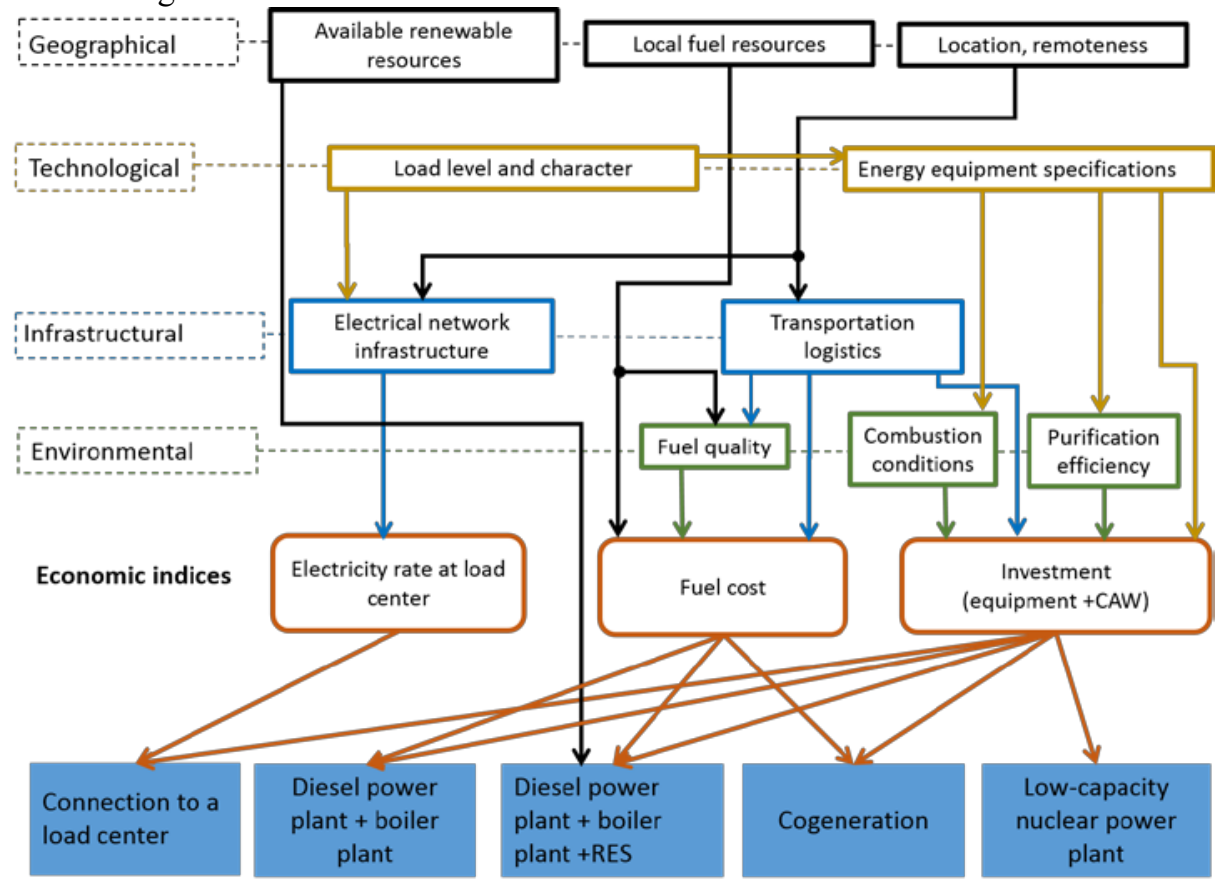

Fig. 4. Interaction of significant factors and their effect on the economic indices of power supply options

Based on the long-term research done for various territories in the eastern regions of the Russian Federation, we determined the boundary values for the characteristics of the main significant factors for economically viable application of alternative options of power supply to the off-grid consumer. The systematization of the research results made it possible to form a scheme of selecting a rational option of power supply according to the characteristics of factors of a certain consumer (Fig. 5).

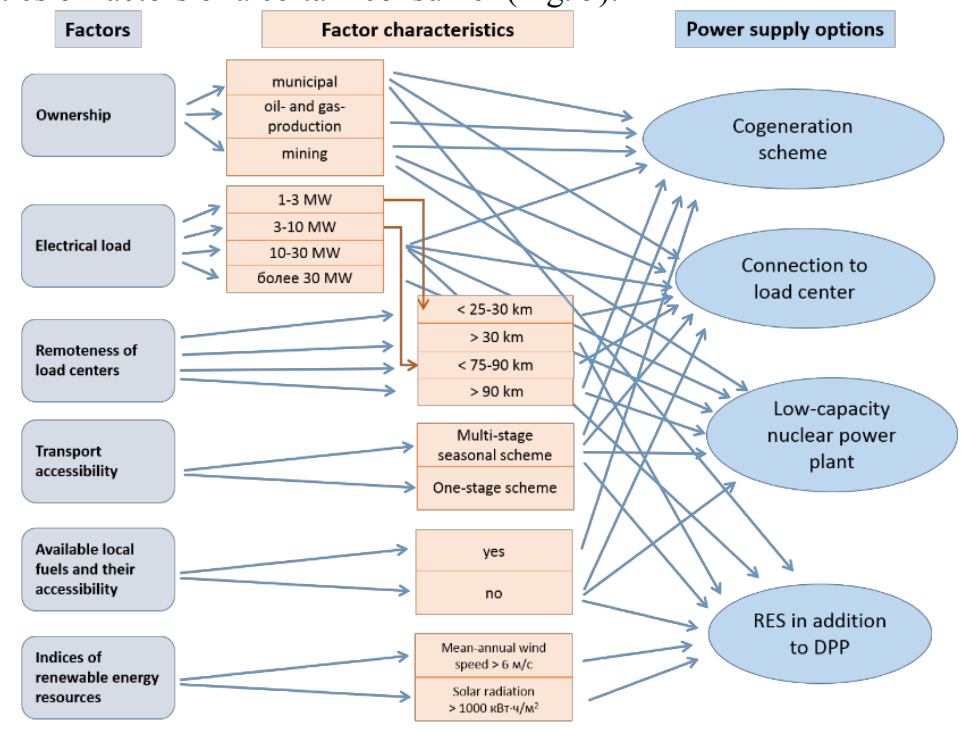


Fig. 5. A scheme of selecting a rational option of power supply to off-grid consumers in the eastern regions

Thus, an option of centralized power supply to a consumer with a load of 1-3 MW in the north-eastern regions can be recommended when the consumer is located at a distance of 25-30 km from the power supply centers [8]. An option for constructing low-capacity nuclear power plant should be considered for mining enterprises with an electric load of above $10 \mathrm{MW}$ when they are situated at a distance over $90 \mathrm{~km}$ from the centers of possible connection to a grid [9]. Construction of renewable energy sources is reasonable for household consumers with the loads below $10 \mathrm{MW}$ that are situated over $30 \mathrm{~km}$ away from power supply centers, and are located within the regions with high metrics for wind- or solar-potential.

\section{Acknowledgements}

The study was conducted under Scientific Project XI.174.2.3 of the Program for Basic Researches from the Siberian Branch of the Russian Academy of Sciences, Reg. No. AAAA-A17-117030310439-8

\section{References}

1. V.E. Zakharov, D.V. Prokhorov, and V.L. Gavrilov. Losses of calorific value of runof-mine coal when delivering to Arctic consumers in the Sakha (Yakutia) Republic. Proceedings of HEI. Energy Sector Problems, No. 5-6, pp.13-22 (2013) (in Russian)

2. S.M. Tkach, and V.L. Gavrilov. On the effect of the "georesource - consumer" process chains on coal losses at power supply to polar areas of Yakutia. Fundamental and applied issues of mining sciences, No. 3, V.1, pp. 213-218 (2016) (in Russian)

3. Fuel and energy complex of the Irkutsk region. Current state, development prospects. Ed. by B.G.Saneev, P.A.Voronin. Moscow: Publishing House "Energia", 230 p. (2013) (in Russian)

4. 2030 Energy Strategy for the Sakha (Yakutia) Republic. Government of the Sakha (Yakutia) Republic. Yakutsk; Irkutsk: "Yakutia" Media Holding, et al., 328 p. (2010) (in Russian)

5. Fuel and Energy Complex of the Irkutsk Region: Current state and development prospects. Ed. by B.G. Saneev and P.A.Voronin, Moscow: Publishing House "Energy", 304 p. (2013) (in Russian)

6. Fuel and Energy Complex of the Baikal Region: Current state and development prospects. Ed. by B.G. Saneev. Novosibirsk: Academic Publishing House GEO, 176 p. (2015) (in Russian)

7. I.Yu. Ivanova, T.F. Tuguzova. Substantiation of rational options of energy-and fuel supply to off-grid consumers in the region: A methodological approach, research results. Energy Policy, No. 4, pp. $42-49$ (2011) (in Russian)

8. I.Yu. Ivanova, T.F. Tuguzova, and N.A. Petrov. A comprehensive efficiency assessment of the options of energy- and fuel supply to off-grid consumers: methodological approaches and research results. $7^{\text {th }}$ Melentiev Theoretical Readings «Forecasting the World and Russian energy development: approaches, problems, solutions», Moscow: ERI RAS, pp. 196-205 (2013) (in Russian)

9. N.I. Voropai, B.G. Saneev, I.Yu. Ivanova, and A.K. Izhbuldin. Comparative efficiency of using low-capacity nuclear power plants in local energy systems of Russia's East. 
Low-capacity nuclear power plants: a new trend in nuclear energy development: V.2. Ed. by A.A. Sarkisov, M.: Akadem-Print Publishers, pp. 59-71 (2015) (in Russian) 